\title{
Selective suppression of consummatory behavior as a function of duration of punishment training
}

DENNIS K. KAMANO, GALESBURG STATE RESEARCH HOSPITAL DENNIS J. ARP, WASHINGTON UNIVERSITY

This study was designed to determine whether the effectiveness of punishment in producing selective suppression of consummatory behavior was dependent upon the length of punishment training. It was found that of two punishment training sessions, during which only the forbidden consummatory response was punished, the shorter (16 trials) tended to temporarily suppress the consummatory act itself without selectively developing any avoidance of the forbidden needreducing object, while the longer ( 32 trials) produced selective avoidance to a significant degree in a later nonpunishment series. The length of punishment training rather than the frequency of punishment itself appeared to be the critical variable in producing selective avoidance. Apparently, the longer training session increased the probability for the punishment effect to become attached to the forbidden consummatory response above and beyond the consummatory act itself.

Punishment is said to be relatively effective in producing avoidance of a specific need-reducing object (NRO) if other related NROs are available. Punishment causes $S$ to selectively avoid or suppress responding to the forbidden NRO and shift to the other substitute NROs. Moreover, $S$ learns that the consummatory act (e.g., eating) itself is not punishable; only the consummatory response to the specific NRO (e.g.. eating a particular food substance) may result in punishment. Punishment, in this case, serves a discriminative function and provides for specificity in consummatory behavior.

Punishment per se has a temporary suppressive effect (Estes, 1944; Skinner, 1953) and, without the presence of alternative NROs, may have the generalized effect of suppressing the consummatory act itself rather than selectively suppressing the consummatory response to the forbidden (punished) NRO. That is, punishment without substitute NROs may not prevent $S$ from selectively avoiding the forbidden NRO. When presented with other relevant NROs, $S$ is just as likely to select the forbidden NRO when the consummatory response is reinstated (i.e., after the temporary suppressive effect has been extinguished) in a later nonpunishment condition.

In those situations where alternative NROs are absent, the effectiveness of punishment in producing avoldance of a specific NRO may be dependent upon the length of punishment training. Whether $S$ associates punishment with the consummatory act itself and falls to associate punishment specifically with the consummatory response to the forbidden NRO may be dependent upon the duration of punishment training. Given two punishment training sessions of different duration, the probability is greater for the shorter of the two to suppress the consummatory act itself without selectively developing strong avoldance towards the forbidden NRO. Consequently, S may not avoid the forbidden NRO in favor of other relevant NROs in a later nonpunishment condition.

The approach of the present study was to designate one of two food substances as the forbidden NRO, and to follow this with punishment training of 16 and 32trial duration during which any consummatory responses toward the forbidden food were punished. The effect of punishment training on S's response to the forbidden food was then tested with the other food present under a nonpunishment condition. The number of trials required to consume either of the two food substances indicated the suppressive effect of punishment on the consummatory act (i.e., eating) itself, and the number of trials required to eat the forbidden food indicated the effect of punishment in developing avoidance of that specific food substance.

\section{Method}

Subjects. The Ss were 22 male Wistar albino rats from the colony maintained at the Galesburg State Research Hospital. They were 60 to 63 days old and weighed between 180 and $240 \mathrm{~g}$ at the start of the experiment.

Apparatus. The apparatus was a $\mathrm{T}$-maze of unpainted plywood with a Plexiglas roof. It was $3.50 \mathrm{in}$. high with a $10.25 \times 3.75$ in. starting box, $12.75 \times 2.75$ in. center alley, 4.75 in. square choice point, and identical $5.75 \times$ 2.75 in. arms with their ends fixed with a plastic food tray. The floor consisted of $1 / 8$ in. brass rods with their centers set $5 / 16$ in. apart. The grid floors on the right and left arms were wired to form two independently electriffable grids, and shock as punishment was delivered through the grid floor at an intensity of $150 \mu \mathrm{a}$.

Procedure. The Ss were housed in individual home cages, handled ad lib, fed 12-15 g Chow Checkers daily for 10 consecutive days, and then fed both chow and white bread (about one-eighth of a slice) for four consecutive days. The Ss were then placed under a $21 \mathrm{~h}$ deprivation schedule which was maintained throughout the experiment. On the day after deprivation, the Ss were placed in a box $9 \times 9 \times 20.5$ in. with a grid floor in which pieces of bread approximately 3/8-in. square and cracked chow in plastic food trays were both available. The Ss were allowed as much time as 
needed to eat and were permitted to eat the food of their choice for $30 \mathrm{sec}$. Two trials were given with bread and chow placed on alternate sides, and all Ss chose bread on both trials. Immediately thereafter, each $S$ was placed in the T-maze for 5 min of exploration and randomly divided into two groups of $11 \mathrm{Ss}$ each.

Punishment training. For this series the center alley of the maze was blocked off at the choice point by a guillotine door, and each $S$ was placed directly into the choice point. The Ss in Group A, when placed in the choice point found bread in the food tray of one arm and nothing in the other arm. Placement of bread was randomly alternated, and shock of approximately .50 sec duration was administered only when contact with bread was made; they were not punished for approaching the bread. They were given two $3 \mathrm{~min}$ trials a day for eight days, making a total of 16 punishment trials.

The Ss in Group B received the same treatment as Group A, except that they were given twice as many punishment trials. They received two $3 \mathrm{~min}$ trials a day for 16 days, making a total of 32 trials.

Test of punishment training. For this nonpunishment series, each trial began by placing $S$ in the starting box of the $T$ maze. Chow and pieces of bread, randomly alternated, were always available for all Ss and shock was never administered. Each $S$ received two $3 \mathrm{~min}$ trials a day until it reached a criterion of eating bread for five consecutive trials.

Resulis

The means and standard deviations of the number of shocks received in 16 trials for Group $A$ and 32 trials for Group B were $4.55 \pm 1.29$, and $6.09 \pm 3.11$ respectively, a nonsignificant difference. Thus, Group B did not receive significantly more shocks (punishment) than Group A despite undergoing twice as many punishment training trials.

In the test of punishment training series in which bread and chow were both available and no shock was administered, Groups $A$ and $B$ both revealed suppression of the consummatory response; they temporarily avoided eating both bread and chow. Group A required an average of $5.18 \pm 6.55$ trials to eat either bread or chow, while Group $B$ required an average of $3.82 \pm$ 4.59 trials, a nonsignificant difference. When eating occurred, eight Ss chose bread and three chose chow in Group A, while all Ss chose chow in Group B.

The mean trials to criterion of eating bread for Groups $A$ and $B$ were $6.45 \pm 6.92$ and $48.82 \pm 36.55$, respectively. Application of the Mann-Whitney U test revealed that Group $A$ with the shorter punishment training session required significantly less trials to reach the criterion of five consecutive trials of bread eating $(Z=3.28, p<.01)$. The amount of bread pieces consumed during the five consecutive bread eating criterion trials was noted as evidence to indicate S's return to bread eating during the criterion trials. The mean bread consumption for Groups $A$ and $B$ were 23.64 and 20.73, respectively.
A qualitative difference between the Ss in Groups A and $B$ was noted in their response to the nonpunitive test series. Six Ss in Group B but none in Group A revealed aggressive responses during the nonpunishment series. The aggressive response consisted of the Ss plunging headlong into the food dish and vigorously scattering the food pieces. Bread and chow were both equally attacked.

\section{Discussion}

Apparently, the length of punishment training is critical in the development of discriminative consummatory behavior. Extended punishment training did increase the probability of discriminative suppression of consummatory behavior. Punishment temporarily suppressed the consummatory response in both groups, but when the response was reinstated, the initial choice of all the Ss in Group B was for the nonforbidden NRO. The initial choice of the $S s$ in Group A indicated a lack of discriminative suppression in that the majority chose the forbidden NRO. The most convincing evidence, however, came from the fact that the Ss in Group B took significantly longer to reach the bread eating criterion in the nonpunishment situation.

It should be noted that extended punishment training was not accompanied by any significant increase in punishment (shock). Therefore, the difference between Groups $A$ and $B$ could not be attributed to the number of punishment received, but rather may be due to the amount of exposure to the threatening punishment training situation. The generalized fear reaction evoked early in training through shock has greater probability for selective attachment to the target response with increased training trials. It appears that the frequency of punishment itself grows less critical with increased opportunity for the punishment effect to become associated with the specific target response.

Although this study has demonstrated that the probability of obtaining selective suppression of consummatory response was a function of the length of punishment training, a concomitant increase in adverse reactions may place some limits on the length of training. Otherwise, the S may demonstrate "neurotic" behavior in the form of alternating bursts of violent behavior as in the case of Hunt \& Schlosberg's (1950) rats. In the present study, the Ss in Group B which received the longer punishment session demonstrated this violent behavior and were not discriminative in their attacking behavior. Such aggressive behavior may be a function of "frustration" and peculiar to the albino rat.

\section{References}

ESTES, W. K. An experimental study of punishment. Psychol. Monogr., 1944, 57, (3 Whole No. 263).

HUNT, J. McV., \& SCHLOSBERG, H. S. The behavior of rats kept continuously in conflict. J. comp. physiol. Psychol., 1950, 43, 351357.

SKINNER, B. F. Science and human behavior. New York: MacMillan, 1953. 